\title{
Fashion cultural product design applying cultural resources of Iksan
}

\author{
Hye Kyung Kim ${ }^{\dagger}$, Mi Kyung Chu, Jeong-Hwa Hong and Hee-Kwan Jeon \\ Dept. of Fashion Design \& Apparel Industry, Wonkwang University, Korea

\section{익산지역 문화 자원을 활용한 패션 문화상품 디자인 개발}

\author{
김혜경 ${ }^{\dagger} \cdot$ 추미경 · 홍정화 · 전희관
}

원광대학교 패션디자인산업학과

\begin{abstract}
This study aims to develop motifs and patterns for fashion cultural product designs in order to promote the Iksan Seodong Festival, which is the most representative festival in Iksan region. The motifs and patterns developed in this study can be used to introduce the distinct traditional culture depicting the legendary Seodong tale. This study used Adobe Illustrator CS4 and Adobe Photoshop CS4 to reconstruct the lotus motifs found from the greenoiled-lotus-motif rafter tile, the atrifact from Iksan Mireuksaji Museum. This lotus motif and the motif based on the Iksan City's logo were applied to a repeating pattern with colorways using the CMYK found from the Iksan city's logo. A total of 24 product designs, including 8 necktie designs, 8 scarf designs, and 8 T-shirts designs, were presented for fashion cultural products. The designs developed in this study can promote not only the local Iksan culture but also the national image of Korea on a global scale.
\end{abstract}

Keywords: fashion cultural product(패션문화상품), cultural resources of Iksan(익산문화자원), necktie(넥타이), $\operatorname{scarf(ㅅㅡㅋㅏㅍㅡ),~T-shirts(ㅌㅣㅅㅕㅊㅡ)~}$

\section{Introduction}

우리가 살고 있는 현대 사회는 두 가지의 상반된 특징을 동시에 지니고 있다고 할 수 있다. 국가나 지역 간의 경계가 모호해지는 글로벌화가 그 특징 중 하나이고, 다른 한 가지는 한 국가나 지역만이 가지고 있는 고유한 문화적 정체성을 유지하거나 재창조하여 그 지역을 다른 지역과 구별하고자 하
는 차별화가 그 특징이다. 이는 문화적 특성을 차 별화하고자 하는 이유는 문화적 요소가 지니는 무 한한 잠재력 때문이라 할 수 있다.

21 세기 현대 사회에서의 문화는 단순히 인간을 이해하는 수단을 넘어 다양한 문화적 요소를 형성 하고, 고객의 감성을 자극하여 부가가치를 창출하 고자 하는 문화 마케팅의 중요한 매개체가 되고 있 다. 이러한 문화 마케팅은 문화 산업 마케팅의 광범 위한 활동으로써 세계 박람회 및 국내 지역 문화

Received 26 May 2014, revised 11 August 2014, accepted 12 August 2014.

본 논문은 2012년도 원광대학교의 교비 지원에 의해서 수행되었음.

${ }^{\dagger}$ Corresponding author (hanel@wonkwang.ac.kr)

This is an Open Access article distributed under the terms of the Creative Commons Attribution Non-Commercial License (http://creativecommons.org/licenses/by-nc/3.0) which permits unrestricted non-commercial use, distribution, and reproduction in any medium, provided the original work is properly cited. 
축제의 감성에 맞추어 커다란 경제 효과를 창출할 수 있다. 한국의 경우도 문화 산업의 글로벌화를 촉진하고, 관련 산업과 유관 기관들의 네트워크를 통한 문화 산업 육성을 위해 2005년 '문화강국 C-KOREA2010」을 수립, 발표하고, 이의 달성을 위 해 국가 역량을 모으고 있다. 또한 1995년 지방 자 치가 본격적으로 도입이 되면서 많은 지방 자치 단 체들이 지역 개발과 지역 이미지 제고 및 지역 경 제 활성화를 위한 이상적인 아이템으로 지역 문화 에 기반을 둔 다양한 행사들을 기획, 추진하고 있 다. 또한 지역 특성과 소비자 감성에 맞는 디자인 의 개발과 상품화로 독창적인 문화적 아이덴티티 를 보여주고자 노력하고 있다. 현재 우리나라 각지 에서는 지역별로 각각의 특성 및 특징을 바탕으로 1,000 개 이상의 지역 축제가 개최되고 있으며, 지역 의 축제를 관광 상품화하여 지역을 홍보하기 위한 지역 마케팅의 수단으로 적극 활용을 하고 있다. 이러한 지역 축제에 대한 관심의 증가가 가속화될 것으로 판단되며, 이러한 상황 속에서 문화 상품은 관광객이 여행 중 거의 필수적으로 지출하는 관광 비용과 관련되어 있어, 지속적인 성장이 가능한 산 업 분야로 평가되고 있다(Kim, Park \& Cho, 2007).

문화상품 개발에 대한 선행연구를 살펴보면, 전 통문양을 모티프로 활용하여 디자인을 개발한 연 구(Kim, Ko, Kim, Kil \& Yang, 2000; Kwon, 2002; Eom, 2004; Choi, Chung, Lee \& Shin, 2006; Kim, Hong \& Kim, 2007; Song, 2010)와 지역 문화자원 및 축제를 활용한 패션 문화상품 개발의 연구가 있다 (Park \& Kim, 2006; Lee \& Kim, 2007; Lee \& Chung, 2008; Kim, 2010; Kim, 2011). 이러한 연구의 주제 는 주로 함평 나비 축제와 광양 매화축제, 여수 세 계박람회 중심으로 이루어져 왔다. 하지만 백제 지 역의 문화자원, 특히 마한 백제 문화권인 익산시의 문화 자원을 활용한 패션문화상품 디자인개발 관 련 연구는 미흡한 실정이다.

전북 익산시는 마한 백제의 문화 유적을 보유한 유서 깊은 지역이지만, 백제의 고도인 부여와 공주 에 비해 상대적으로 주목을 받지 못한 것은 사실이 다. 하지만 미륵사지 유물과 왕궁리 유적터 등이 발굴되면서 새롭게 주목을 받게 되었고, 역사적 유 물 이외에도 익산은 독특한 축제를 개최함으로써 지
역문화를 알리는데 큰 영향력을 미치고 있다. 서동 요로 선화공주의 사랑을 얻고 백제 30 대 무왕에 오 른 후 삼국통일의 웅지를 펼치려 했던 서동의 사랑 이야기에 바탕을 둔 '익산서동축제'는 1968년 마한 민속제전에서 유래하여 오늘에까지 이어져 내려오 고 있다. 또 하나의 특색 있는 축제로는 세계 수준 의 규모를 자랑하는 익산보석박물관에서 개최되는 대한민국 유일한 귀금속 전시회인 '익산보석대축제' 등이 있다.

이처럼 풍부한 문화 유적과 차별화된 축제를 개 최하고 있는 익산시는 방문객을 끌어들이기 위한 다양한 노력을 기울이고 있다. 하지만 문화 유적과 관련된 관광지에서 판매되는 상품은 지역의 문화 적 특성을 반영한 상품이 아닌 일반적인 관광 상품 이 대부분이어서 방문객들의 구매를 끌어내기에는 부족하다고 할 수 있다. 또한 개최되고 있는 축제 행사는 시민 및 관광객들이 체험할 수 있는 부대행 사들을 중심으로 운영이 되고 있으며, 축제의 특성 이나 익산시의 문화적 가치를 함축하고 있는 문화 상품 개발은 미비한 실정이다.

따라서 본 연구는 익산지역의 대표적인 문화자 원을 활용하여 익산을 방문하는 소비자들의 감성 에 부합되고, 익산시의 가치를 담은 대표적인 패션 문화상품 디자인을 개발하는 데 목적이 있다.

\section{Background}

\section{Fashion cultural product}

최근 정부는 국내 관광 활성화를 위해 '관광 주 간’을 지정하고, 지방 자치 단체 및 관광업계 등과 합동으로 연계하여 신규 여행 수요를 대폭 창출해 나갈 계획을 가지고 있다. 이러한 정부의 적극적인 지원책과 가족 중심의 테마 여행 증가에 따라 각 지역들은 관광객을 유치하기 위한 다양한 전략을 개발하고 있다.

그 전략의 대표적인 특징으로는 여타 지역과 차 별화되는 지역 문화 자원을 활용하고, 이에 기반을 둔 다양한 행사를 기획하여 행사 방문객들에게 각 지역의 특성을 전달할 수 있는 문화 상품을 개발하 는 것이다. 이러한 문화 상품이 가치를 갖기 위해 서는 그 지역의 문화와 역사성을 담고 있어야 하며, 
다른 지역과 차별화된 독특성과 매력성을 지니고 있어야 한다.

한편, 문화 상품에 대한 개념은 연구자에 따라서 다양한 관점에서 정의하고 있다. 2000년도 Ministry of Culture and Tourism에서 발표한 자료에 의하면 문화 상품을 ‘문화산업’이 낳은 모든 결과물로 문화 의 영역이 경제적 영역과 결합함으로써 산업의 생 산 및 소비의 대상물로 나타나게 되는 모든 분야로 정의하였다. $\operatorname{Kim}(2002)$ 은 각 나라의 고유한 문화의 영역이 경제적 영역과 결함함으로써 산업적 생산 및 소비의 대상물로 나타나게 되는 모든 분야를 의 미한다고 하였다. Hyun \& Bae(2007)은 문화 상품 을 영화, 도서, 음반, 신문·잡지, 애니메이션, 출판, 텔레비전 프로그램부터 한국적인 소재, 표현 기법, 제작 기술 등을 차용한 공예 분야, 생활 문화 상품, 미술품 복제, 캐릭터 상품을 포괄한다고 하였다.

문화 상품은 일정한 용도와 한정된 물질적, 경제 적 효용 가치를 지니는 일반적인 상품보다는 상위 의 개념으로 한 민족 내지는 지역의 고유한 정신적, 문화적 가치가 경제적인 효용 가치와 결합하여 생 산되는 유- 무형의 모든 상품을 포함하는 광범위한 개념을 지칭한다(Lee, 2002). 문화 상품은 축제 개 최로 인해 형성된 장소 자산과 이를 토대로 변화하 고자하는 지역의 이미지를 외부에 알리고, 축제의 홍보수단 및 지역 심벌 이미지로 적극 활용할 수 있 는 것이다. 그리고 문화 상품 판매를 통해 축제 자 체의 수익을 창출하고, 이러한 수익 창출은 안정적 인 축제의 운영뿐만 아니라, 축제의 질적 향상에 기 여한다(Lee, 2005).

패션 문화 상품에 대한 정의도 연구자에 따라 다 양한데, Hong(2001)은 국가 또는 지역의 문화적 요소 나 이미지를 활용한 패션 상품으로 정의하였다. Lee, Kim and Lee(2005) 연구에서는 한국 문화의 특성을 반영한 상품으로서, 의류, 패션 잡화, 관광 기념품, 티셔츠, 모자, 보석, 액세서리, 한복, 생활한복, 그리고 섬유 공예품으로 정의하였다. 또한 Hyun(2006)은 자국 의 전통 문화나 이미지에 당시의 트렌드가 반영된 직물을 이용한 상품으로, $\mathrm{Cho(2007)는} \mathrm{전통적} \mathrm{요소}$ 와 한국의 현대적 이미지까지 포함하는 문화적 정체 성을 표현하는 패션 상품으로 정의하고 있다.

이처럼 패션 문화 상품은 상품 자체의 판매보다
는 이미지로 판매되는 고부가가치의 문화 상품으 로써 지역 문화의 독창적 이미지를 알리고, 더불어 축제의 경제적 효율성 그리고 관광객 유치에 활용 하기 위한 상징적인 아이템이라 할 수 있다.

하지만 현재 익산시에서는 전문적인 문화상품을 개발하고 운영하는 조직이 없어서 양질의 상품을 개 발하지 못하고 있는 실정이다. 여타 지역에서 개발 된 상품의 복제품 위주로 판매되고 있으며, 상품 판 매 장소도 소규모의 판매점으로 타 지역과 차별적 특성을 찾기가 어렵다. 이러한 이유로 방문객들의 소비욕구를 이끌어낼만한 상품이 부재한 실정이다.

패션 문화 상품의 종류 및 분류에 대한 기준도 다양하게 제시되고 있는데, 2000년도 Ministry of Culture and Tourism의 발표에 의하면, 패션관련 문 화 상품을 섬유 공예 문화 상품에 포함시킨 적이 있다. 섬유 공예 문화 상품은 장식 용품, 관광 기념 품, 생활 문화 상품으로 분류하여 장식 용품에는 매듭, 인형, 노리개, 부책, 장석, 보석함 등이 포함 되고, 관광 기념품에는 가방, 넥타이, 복주머니를 포함시켰고, 생활 문화 상품에는 이불, 가발, 실내 화, 보료, 방석, 생활 한복, 앞치마, 거울, 보자기 등 을 포함시켜 분류를 하였다.

충청 지역 국립박물관을 중심으로 한 백제 문화 상품 현황을 조사한 Lee and $\operatorname{Kim}(2007)$ 의 연구에 의하면, 공주박물관에서 판매되고 있는 상품 중에 서 문방 용품은 $26 \%$, 생활 용품은 $12 \%$, 장신구/잡화 는 $9 \%$ 가 백제의 특징을 담은 상품으로 나타났고, 평균으로 보면 $12 \%$ 만이 백제의 특징을 담은 상품 이었다. 국립부여박물관에서 판매되고 있는 문화 상 품 중 평균 $16 \%$ 만이 백제의 특징을 담고 있는 상 품이고, 이중 부여 지역의 특징을 지니고 있는 상 품은 $5 \%$ 에 불과하였다. 이처럼 지역 문화 상품 판 매의 중심으로 볼 수 있는 국립박물관에서 판매되 는 상품조차도 지역의 특성을 반영한 상품이 아주 미흡한 실정이다.

\section{Local cultural resources and symbol of Iksan}

익산시는 역사적으로 유래가 깊은 지역이므로, 다 양한 문화 유적을 보유하고 있는 곳이다. 익산시 문 화 유적 중에서 가장 주목을 받는 곳은 미륵사지석 탑과 미륵사지 출토 유물이다. 특히 미륵사지에 소 
재한 석탑은 한국에 남아있는 석탑 가운데 가장 오 래된 것으로 국보 제 11 호로 지정되어 있다. 이 석 탑을 우리나라 최고(백제, 7세기)의 석탑으로 보는 이유는 그 이전에 성행하였던 탑의 양식과 달리 목 탑의 각부 양식을 나무가 아닌 돌로써 충실하게 재 현하였기 때문으로 본다. 또한 사리장엄구에서는 금 제사리호를 비롯하여 금제사리봉안기, 금제쪽집게, 금괴, 금제귀걸이, 은제관식, 금제합, 금실, 유리구
슬, 유리판 등 유물이 총 19종 683점 출토되었다. 백제 무왕의 천도지인 왕궁리 유적과 국보 제 289 호 왕궁리 석탑이 있으며, 고려 충목왕 원년(1345 년)에 건축된 보물 825 호 숭림사 보광전도 익산을 대표하는 문화 자원이다.

익산지역의 문화자원 현황은 〈Table 1〉에서 보 는 바와 같다.

익산시를 상징하는 상징물로는 익산미륵사지석

$\langle$ Table 1〉 Cultural resources of Iksan region

\begin{tabular}{c|c|c|c}
\hline Mireuksaji Stone Pagoda & Wanggungri Remains & $\begin{array}{c}\text { Wanggungri 5-story Stone } \\
\text { Pagoda }\end{array}$ & Mireuksaji Danggan \\
\hline National Treasure No. 11 & Historic Site No. 408 & National Treasure No. 289 & Treasure No. 236 \\
\hline Jeseoksaji & Soongrim Temple Boguangieon & Godori Stone Buddha Statue & Gilt-bronze incense burner \\
\hline Historic Site No. 405 & Treasured Article No. 825 & Treasured Article No.46 & Treasure No. 1753 \\
\hline & & & \\
\hline
\end{tabular}

$\langle$ Table 2〉 Symbols for Iksan city

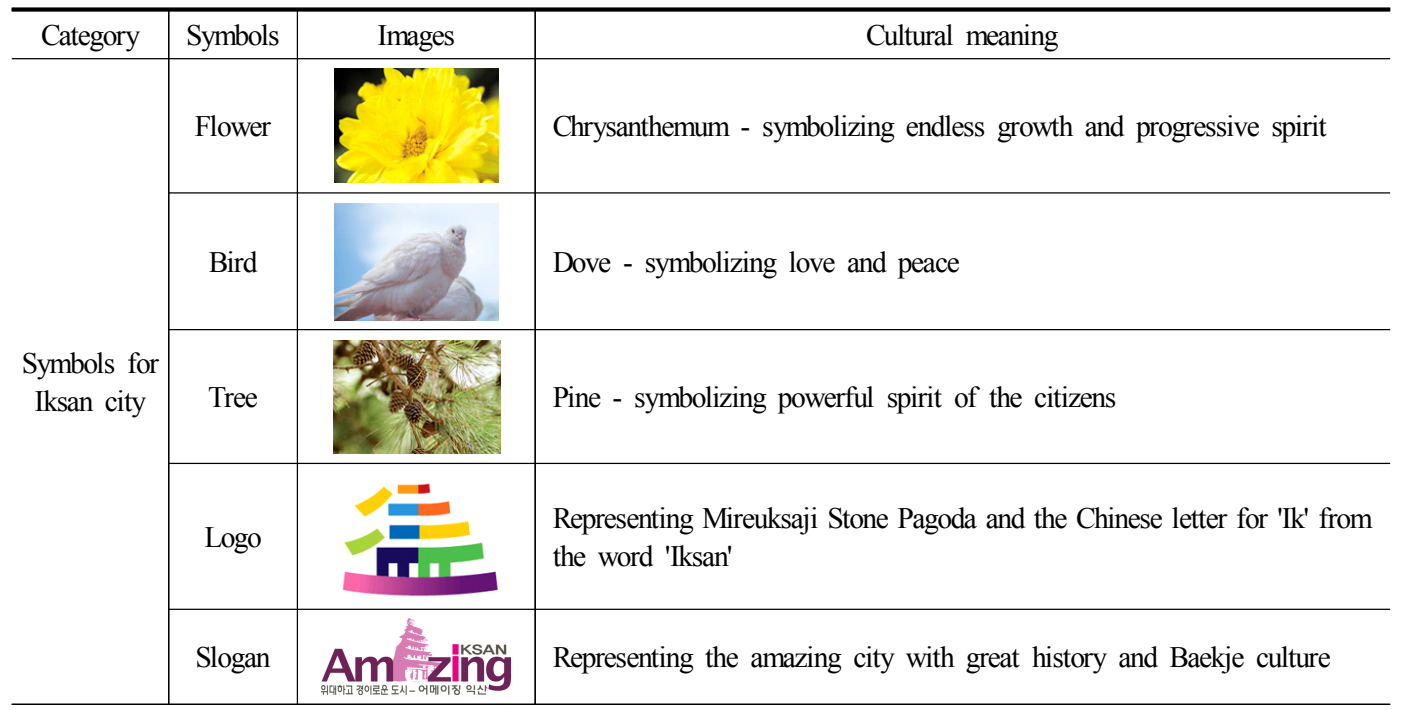


탑을 모티프로 한 로고와 백제, 마한의 위대한 역 사문화도시, 대한민국 식품산업의 메카이자 아시아 식품수도로 거듭날 놀라운 도시 익산을 의미하는 ‘Amazing IKSAN'의 브랜드 슬로건이 있다. 여기에 시화인 국화, 시목으로는 소나무, 시조로 비둘기가 있다(Table 2).

\section{Festival of Iksan}

현재 우리 사회에서 통용되는 축제의 개념은 '특 정한 축제조직에 의해서 불특정 다수를 대상으로 년중의 일정한 시점에 짧게는 하루, 길게는 일주일 동안 특정한 의례행위와 여러 가지 오락, 놀이, 문 화예술, 체육 프로그램으로 구성되는 행사'를 말하 며, 여기에는 대학축제, 거리축제, 지역축제 등이 있 다(Park \& Kim, 2006). 오늘날 지역축제는 지역의 다양한 문화적 현상을 포괄하는 개념으로 확대되고 있는데, 좁은 의미로 보면 지역과 관련이 있는 역사 적 자원을 계승, 발전시켜 문화 축제화한 것을 의미 하고, 보다 확대된 의미로 보면 축제 외에도 문화제 나 예술제와 같은 포괄적인 문화행사를 포함한다고 할 수 있다. 그러므로 지역축제는 말 그대로 지역의 역사와 전통을 바탕으로 지역주민이 주체가 되어 연출하는 지역의 자존과 화합행사이기 때문에, 지 역 문화의 계승, 발전에 의의가 있다(Kim, 2007).

익산시에서 개최되는 서동축제(마한민속예술제) 는 국경을 초월한 선화공주와 서동의 사랑과 서동 요의 본 고장임을 알리기 위해 1966년 10월부터 시 작된 문화축제다. 익산이 삼한시대 마한 54국의 중 심지로서, 역사적인 자긍심을 갖고 개최하고 있는 축제로 2004년부터는 ‘익산서동축제'로 진행되어 오 고 있다.

이는 익산지역이 서동의 탄생지이면서 마한의 도읍지이자 백제 말기의 수도 혹은 별도로 알려져 있고, 또한 976년 발굴된 장방형의 왕궁성, 무왕과 선화비의 쌍릉, 삼국유사 무왕조에 전해오는 국립 사찰격인 미륵사, 금마면 서고도리 연동마을의 서 동 어머니의 축실처설 등의 역사적 배경이 되기 때 문이다. 그리고 매년 서동과 선화의 사랑이야기를 현대적인 시각으로 구성하여 시민축제로 유치하고 있기 때문이다.

한편, 또 다른 축제로는 ‘익산 보석 대축제’로써
익산시 왕궁면 백제 왕궁터에서 출토된 1,400 년 전 의 금도가니, 유리도가니, 철도가니 등을 중심으로 신비의 보석 가공터인 왕궁지역을 중심으로 한 주 얼 팰리스로 전국 유일의 보석축제다. 이렇게 익산 은 보석과 깊은 인연을 맺고 있는데, 이는 백제 후 기 무왕 때 조성된 왕궁면 왕궁 유적지에서 금·유 리·철 도가니가 등이 발견된 것으로 시작되었다 고 볼 수 있다. 익산시에서는 귀금속 보석 산업 클 러스터사업을 추진하여 '대한민국의 보석도시 익 산'의 재도약을 이루고자 1999년부터 축제를 개최 하게 지금에 이르고 있다. 이 축제 기간에는 주얼 팰 리스 60 여 개 업체들의 화려한 보석들과 명장들의 정성과 혼이 담긴 작품 전시들은 보석도시 익산의 숨결을 전해주는 축제로 1년에 2회 개최되고 있다.

이처럼 독특한 주제를 가지고 축제를 개최하고 있지만, 축제는 전시 및 체험 중심으로만 운영되고 있으며, 축제 방문객들이 익산시와 축제에 대한 기 억을 간직할 만한 특징을 가진 문화 상품을 구매할 수 있는 여건은 미흡한 실정이다.

\section{Methods}

본 연구에서는 기본 모티프 선정 및 개발에 있어 서는 익산시를 대표할 수 있는 문화적 자원의 특성 을 잘 나타낼 수 있도록 방향을 설정하였다. 이에 따라 익산의 대표적인 문화자원인 미륵사지석탑과 미륵사지 유적지에서 발굴된 녹유서까래기와를 기 본 모티프로 설정하였다. 선정된 2가지 모티프를 Adobe Illustrator CS4를 이용하여 새로운 조형적 형 태의 응용 모티프로 전개하고, 이 응용 모티프를 Adobe Photoshop CS4를 이용하여 색상을 적용하고, 형태 의 변형과 조합 과정을 통해 패턴화하는 작업을 진 행하였다. 각각의 기본 모티프에 대해 형태 변형과 색상 적용을 달리하여 각각 2 개의 응용 모티프로 확장시켰다. 이렇게 확장된 응용 모티프는 확대와 축소, 반전과 회전, 중첩과 재배치 등을 한 후 평이 음과 all-over로 패턴을 전개하여 모두 8개의 패턴 을 개발하였다. 개발된 8 개의 패턴은 다시 각각의 패턴별로 또는 패턴 간의 조합과 변형을 통해 넥타 이 8점, 스카프 8점, 티셔츠 8점에 적용을 시켜 총 24 종의 패션문화상품을 개발하였다. 모티프에 적용 
된 색상은 익산시를 대표하는 문화 상품을 개발하 는 목적에 부합되도록 익산시 브랜드 슬로건에 사 용되는 $\mathrm{CMYK}$ 를 그대로 적용하였다. 이는 현재 익 산시에서 홍보물이나 관광지 등에서 광범위하게 사용하고 있는 컬러를 문화 상품에도 동일하게 사 용함으로써 통일감과 친근감을 부여할 수 있기 때 문이다. 이를 통해 문화 상품을 구매하는 방문객들 에게 익산의 이미지를 지속시키는 효과를 기대할 수 있을 것으로 본다.

\section{Results and Discussion}

\section{Development of design motif}

\section{1) Motif 1 using Mireuksaji Stone Pagoda}

모티프 1은 익산을 대표하는 미륵사지석탑의 형 태를 응용한 익산시의 로고를 재구성한 것으로, 백 제문화 유산인 미륵사지석탑과 익산의 한자 표기 첫 글자인 '더할 익(益)'의 모양을 상징적으로 보여 주고 있다.

이러한 모티프를 단순화 시킨 응용과정에서는 기 본 모티프의 특징이 가장 잘 드러나는 범위에서 탑 의 직선미를 살린 형태와 곡선미를 살린 2 가지 형
태로 구성하였다. 색상은 익산시의 도시 이미지와 의 통일성을 위해 기존 브랜드 슬로건에 나타난 주 요색상을 사용하였다. 모티프 1-1은 곡선형태의 이 미지를 자연스럽게 강조하기 위하여 그라데이션 기법을 활용하였고, 모티프 1-2는 탑의 원형에 가 까운 느낌이 살아나도록 직선의 형태로 구성을 하 였다. 패턴 전개는 응용 모티프를 회전, 좌우, 상하 반전을 시켜 평이음으로 패턴을 전개하였다. 이상 의 내용을 정리하면 〈Table 3 〉과 같다.

\section{2) Motif 2 using lotus motif}

녹유서까래기와는 엽의 연화문 형태를 한 연목 와로서 완전한 형태로 출토되었다. 표면에 칠한 녹 색의 유약은 기와의 두께와 소성도에 따라서 색상 의 차이를 보이고 있다. 연목와는 서까래기와의 일 종인 특수기와로 둥글고 긴 연목의 끝에 부착하여 목제의 부식을 막고, 장식을 겸하는 용도로 사용되 었다. 화판부에는 7엽의 연판을 배치하였고, 화판 의 길이에 비해 폭이 넓어 도톰하고, 화판 사이의 자연스럽게 연결된 돌기부분과 끝부분이 연목와를 더욱 돋보이게 한다.

모티프 2는 익산 미륵사지 유물인 녹유서까래기 와의 문양을 모티프로 재구성하여 패턴으로 적용

〈Table 3〉 Pattern development using Mireuksaji Stone Pagoda

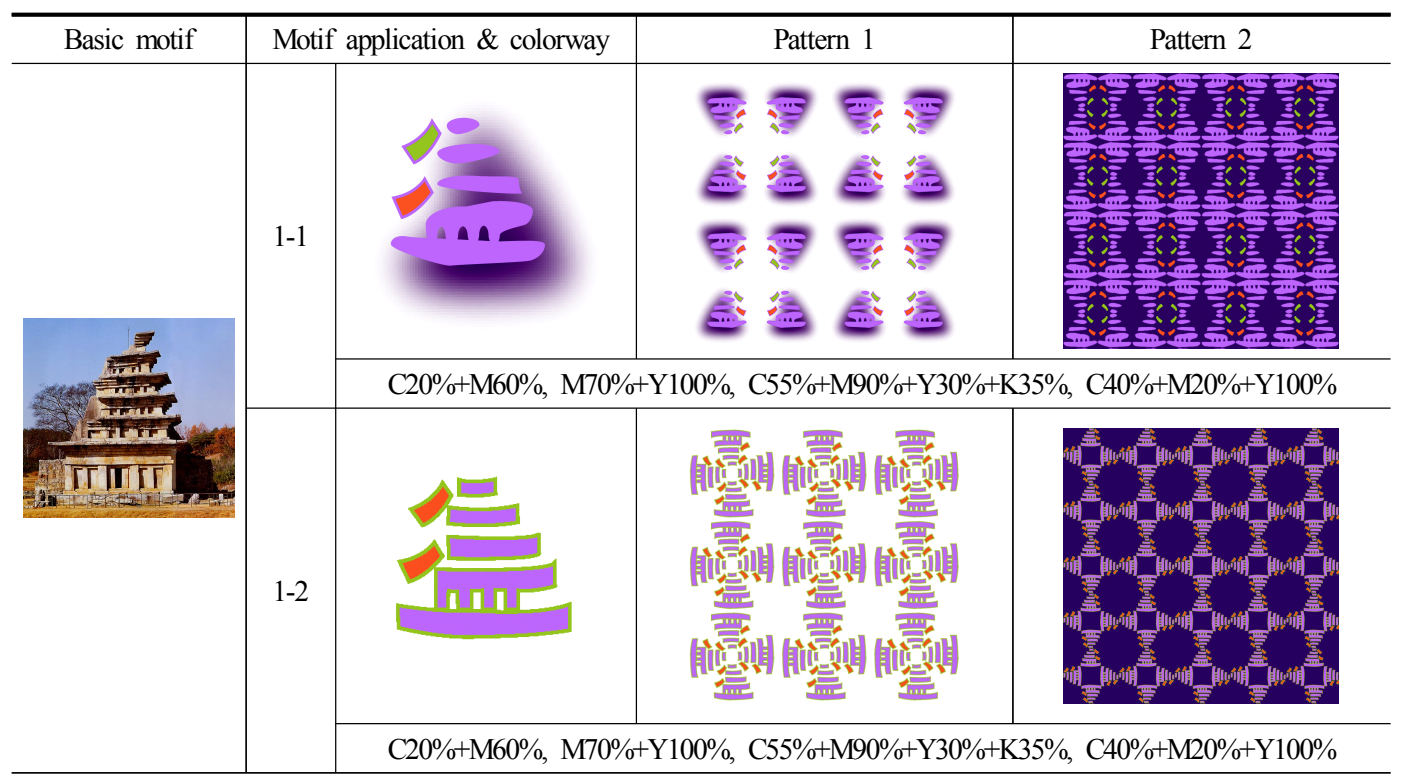


한 것이다. 모티프의 색상 역시 익산시 브랜드 슬 로건에 나타난 주요 색상을 그대로 이용하여 기본 모티프의 특징적 요소를 반영하여 단순화시켜 재 구성한 모티프에 색상을 적용하여 2개의 응용 모티 프로 전개하였다. 2 개의 응용 모티프는 이미지의 확대와 축소를 통한 단순 반복 배열로 패턴을 전개 표현함으로써 심플함을 나타냈으며, 패턴 2는 응용 모티프를 확대와 축소, 채도, 명도 그리고 불투명도
를 조정한 이미지를 활용하여 all-over 패턴으로 전 개하였다. 이를 정리하면 〈Table 4〉와 같다.

\section{Development of fashion cultural product design}

1) Necktie design

기본 모티프 1 과 2 를 활용한 넥타이 디자인 개 발은 응용 모티프를 확대와 축소, 반전과 회전, 재

$\langle$ Table 4〉 Pattern development using lotus motif

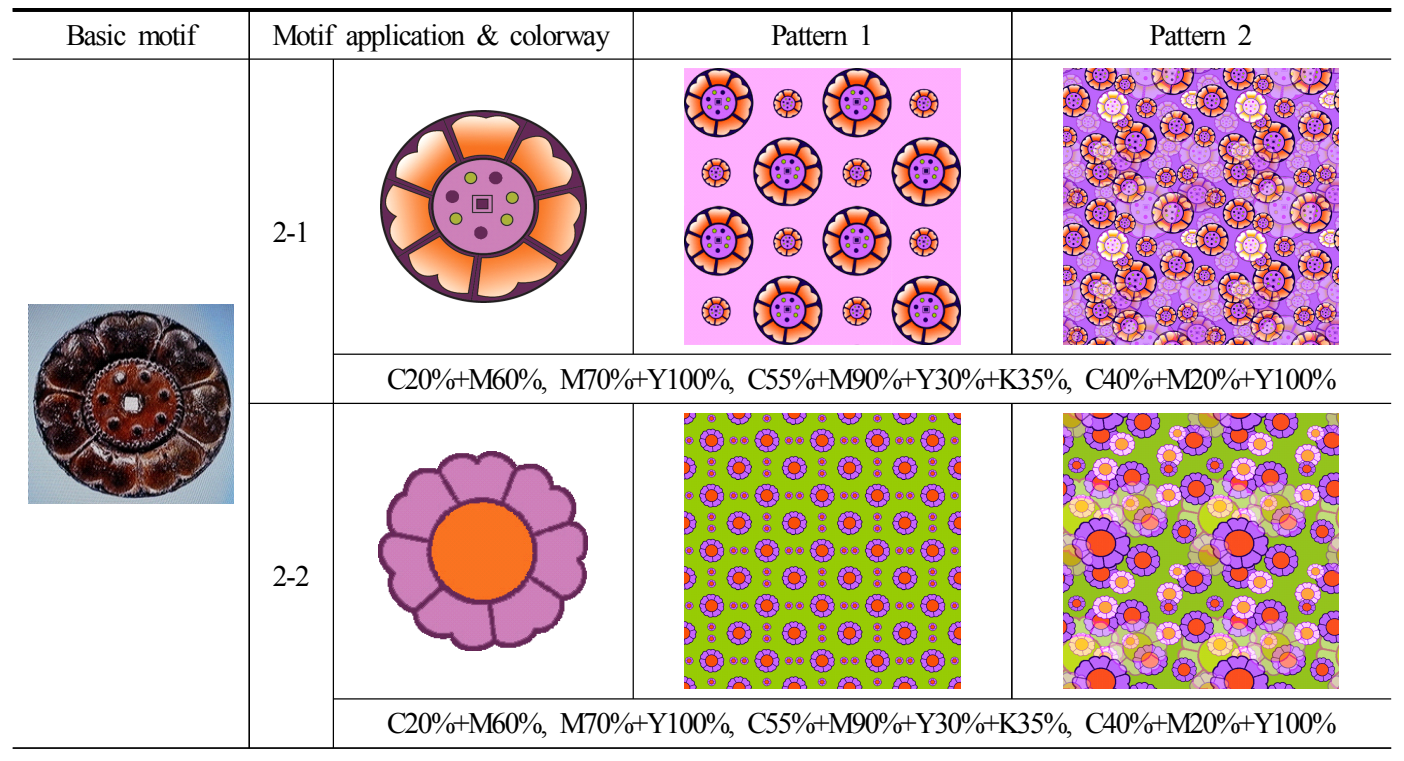

$\langle$ Table 5〉 Necktie design

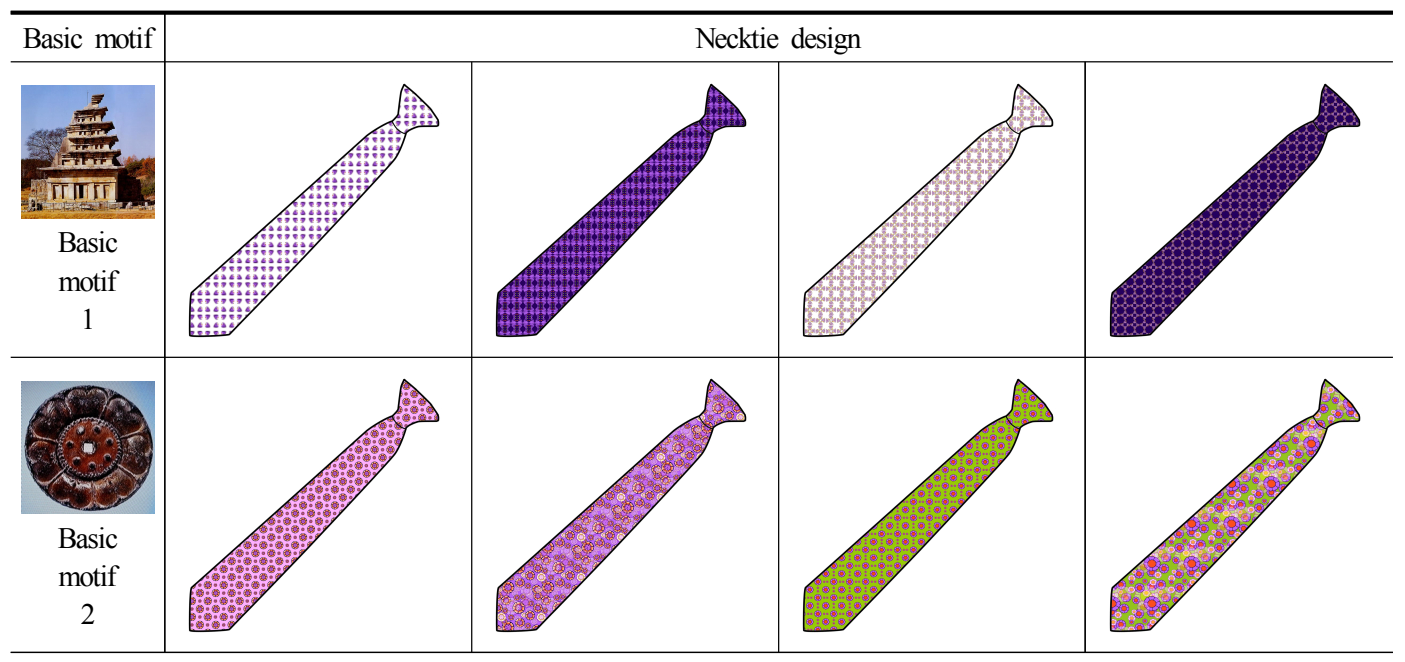


배열, all-over 패턴으로 전개한 패턴 1 과 패턴 2 를 45 도 회전시켜 넥타이에 적용함으로써 모던하고 세 련된 이미지를 나타내도록 하였다. 넥타이 디자인 개발은 〈Table 5〉와 같다.

\section{2) Scarf design}

기본 모티프 1을 활용한 스카프 디자인은 응용 모티프 1-1과 1-2를 조합하여 회전과 반복, 확대와 축소를 통해 각 모티프의 특성이 잘 나타나도록 심 플하게 표현한 디자인과 사각 스카프의 입체적 이 미지 표현을 위해 대칭 구조의 형태로 문양을 배치 함으로써 한국적이면서도 독특한 세련미를 갖도록
디자인 개발하였다. 기본 모티프 2 를 활용한 스카프 디자인은 심플함을 표현한 패턴 1과 화사함과 동양 적인 미를 강조한 패턴 2 를 조합, 재배치, 대각선 대 칭 배열, all-over로 디자인을 전개하였다. 이를 정리 한 내용은 〈Table 6)과 같다.

\section{3) T-shirts design}

티셔츠 디자인은 일반적으로 활용도가 높은 티 셔츠 형태인 반소매 박스형에 전개를 하였다. 기본 모티프 1 과 2를 활용하여 심플하면서도 모티프의 특성이 잘 나타나도록 디자인을 전개하였다. 기본 모티프를 단순화한 이미지를 티셔츠 전면에 배치

$\langle$ Table 6〉 Scarf design

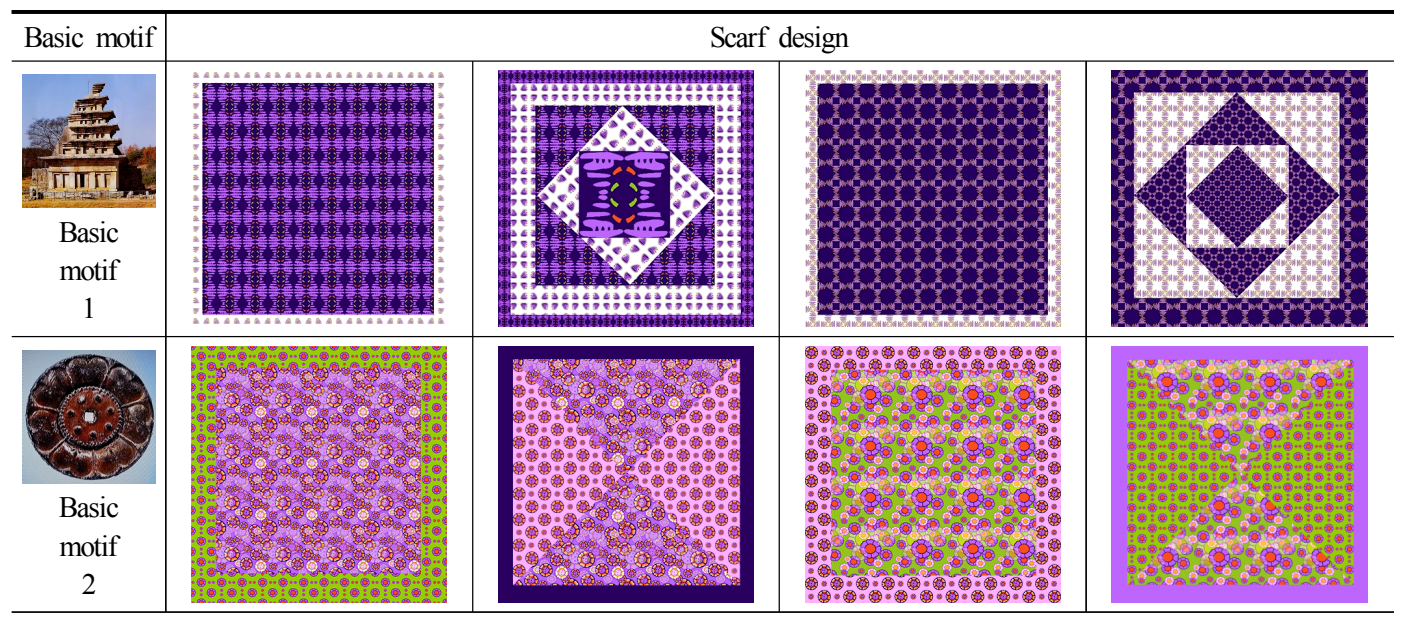

$\langle$ Table 7〉 T-Shirts design

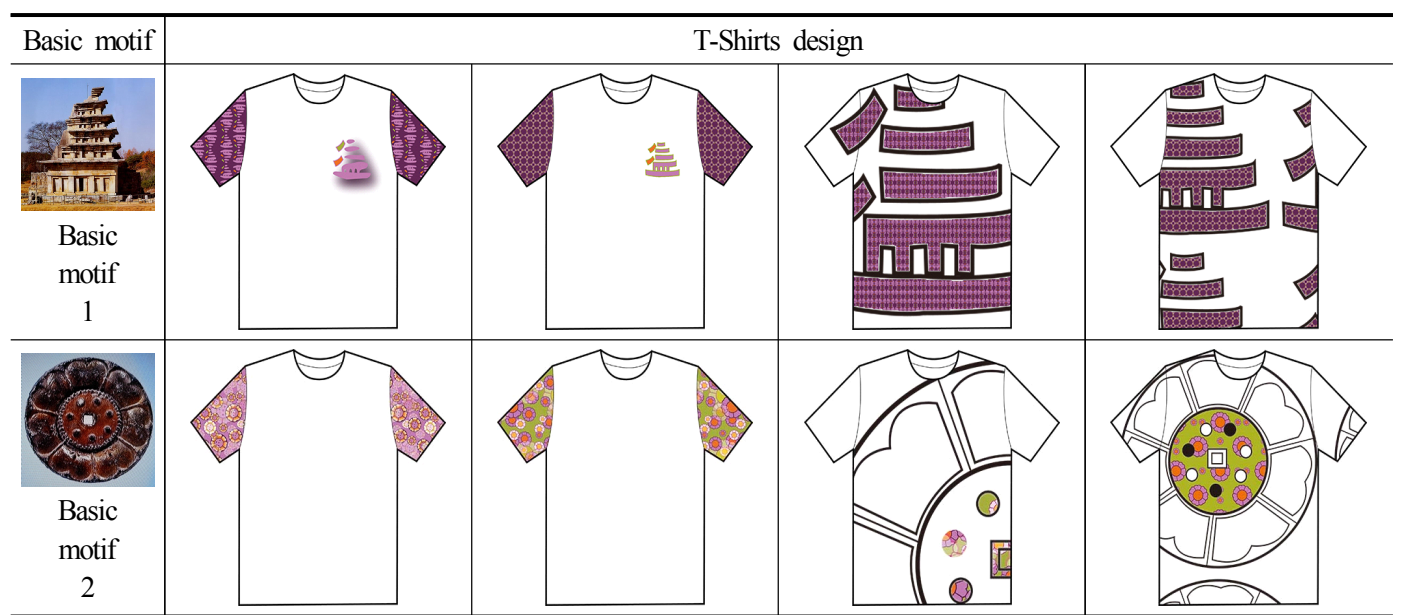


하고, 이미지 내부에는 응용 모티프를 활용한 패턴 의 이미지를 넣어서 장식적인 요소가 나타나도록 하였다. 티셔츠 디자인 전개에 대한 내용을 정리하 면〈Table 7〉과 같다.

\section{Conclusion}

세계화가 급속히 진행되고, 경쟁이 심화되는 현 대 사회에서 국가와 지역은 경쟁에서 살아남기 위 한 다양한 전략을 개발해야 하는 절박한 상황에 놓 여 있다. 경쟁력 강화를 위한 전략은 국가와 지역 에 방문객을 유인할 수 있는 방향으로 전개되어야 한다. 이 전략의 핵심은 문화적 차별성이다. 타 국 가나 지역에 없는 문화적 독특함을 현대적인 트렌 드에 적합하게 개발하는 것이 관건이 될 수 있다.

최근 국내 관광에 대한 수요가 꾸준히 증가하고 있는 시점에서 각 지자체들은 방문객 유치를 위한 다양한 노력을 기울이고 있다. 이를 위해서는 지역 만의 특화된 문화 자원을 방문객들의 감성에 맞게 재해석하고, 이를 기반으로 한 다양한 상품을 개발 하는 것이 필요한 시점이다.

본 연구는 익산 지역만이 가지고 있는 지역 문화 의 특성을 응용하여 소비자의 감성에 다가갈 수 있 는 패션 문화 상품 디자인을 개발하고자 하였다. 이를 위해 익산시를 대표하는 지역 문화 자원을 모 티프로 하여 익산시를 찾아오는 방문객들의 실생 활에 도움이 될 수 있는 패션 문화 상품인 넥타이, 스카프, 티셔츠에 적용하였다.

이에 본 연구에서는 미륵사지석탑과 미륵사지 유물인 녹유서까래기와 문양의 2 가지를 모티프로 재구성하여 패턴으로 적용하였다. 설정된 각 모티 프마다 색상의 변화와 전환, 혼합 등을 통해 4 개의 모티프로 확장시켰으며, 각 모티프를 다른 형태로 반복시켜 2 개의 응용 패턴으로 전개하였다. 기본 모티프 디자인은 본 연구에서 전개하고자 하는 넥 타이, 스카프, 티셔츠에 적합하도록 디자인의 방향 을 설정하였다. 모티프에 대한 기본 색상은 익산시 의 이미지와의 통일성을 강조하기 위해 익산시 브 랜드 슬로건에 사용하는 $\mathrm{CMYK}$ 를 그대로 적용하 였다.

향후 본 연구에서 개발한 패턴디자인은 제시한
아이템 이외에도 모자, 가방, 문구류 등 다양한 상 품 군으로 패턴을 적용시킬 수 있도록 하였기 때문 에 활용도면에서 그 효용가치가 높을 것으로 기대 한다. 본 연구에서 개발된 패션 문화 상품 디자인 이 익산 지역의 문화적 가치를 알리고, 타 지역과 의 경쟁력 확보를 위한 결과물로 발전되길 바란다. 앞으로 후속 연구에서는 익산시 문화 유적지에서 판매되고 있는 문화 상품에 대한 실증적인 조사 연 구를 통해 방문객들에게 필요한 차별화된 패션문 화상품 디자인 개발을 진행하고자 한다.

\section{References}

Cho, Y. J.(2007). Foreign visitors' attitude toward fashion cultural products. Unpublished doctoral dissertation, Seoul National University, Seoul, Korea.

Choi, S. Y., Chung, K. H., Lee, M. S., \& Shin, Y. S. (2006). A study on the development of fashion cultural goods applying traditional Jokakbo. Journal of the Korean Home Economics Association, 44(10), 91-100.

Eom, K. H.(2004). The study on development of cultural goods design applying Korean traditional embroidery pattern. Journal of the Korean Society of Design Culture, 10(2), 107-113.

Hong, H. S., Jang, A. R., Hyon, J. E., \& Kim, H. M. (2001). Trourism market segmentation in Cheju Island based on fashion image of clothing souvenir and characteristics of sub-segments. Journal of the Korean Society of Clothing and Textiles, 25(2), 303-314.

Hyun, S. H., \& Bae, S. J.(2007). A study on the utilization of Korea tradition patterns for fashion cultural products. Journal of the Korea Society of Clothing and Textiles, 31(8), 1252-1261.

Hyun, S. H.(2006). Design development of fashion culture products using traditional Korea. Unpublished doctoral dissertation, Chonnam National University, Gwangju, Korea.

Kim, H. S.(2002). A study on cultural product design 
development. Journal of Korean Society of Design Science, 15(1), 299-308.

Kim, K. M., Hong, J. M., \& Kim, K. Y.(2007). Utility of Korean traditional patterns for cultural product development: An examination of Yeongcheon area. The Journal of Korean Traditional Costume, 10(2), 41-47.

Kim, M. Y., Park, J. H., \& Cho, Y. H.(2007). A study on the relationships among characteristics of destination, personal meaning toward travel and souvenir choice behavior. Journal of Tourism Research, 31(1), 77-96.

Kim, S. Y.(2010). Design development for fashion cultural products by use of traditional floral wall patterns. The Research Journal of the Costume Culture, 18(4), 731-740.

Kim, S. Y.(2011). Use of traditional mask images in design development for fashion-cultural products. The Research Journal of the Costume Culture, 19(3), 460-472.

Kim, U. B., Ko, K. H., Kim, S. W., Kil, T. Y., \& Yang, S. W.(2000). A study on the development of cultural goods utilizing Korean traditional pattern-focusing on Kyongju National Museum's Collections-. Bulletin of Korean Society of Basic Design \& Art, 1(2), 77-90.

Kim, Y. R.(2007). A case study on souvenirson for brand strategy of the regional festival. Journal of Communication Design, 25(0), 113-125.

Kwon, M. O.(2002). The development of traditional pattern-applied cultural products and public relations. The Journal of Publishing \& Magazine, 10(1), 161-178.

Lee, J. H., Kim, M. J., \& Lee, J. M.(2005). A study on marketing strategies for the high-value-added cultural fashion products in Korea. Journal of the Korea Society of Clothing and Textiles, 29(7), 968-977.

Lee, J. M.(2002). A study for the fashioned cultural goods development based on the local culture: With priority given to the cultural goods development applied by the butterfly character of Hampyung. Unpublished master's thesis, Ewha Womans University, Seoul, Korea.

Lee, M. S., \& Chung, K. H.(2008). Development of cultural tourism products for promoting Hampyeong butterfly festival. Journal of the Korean Society of Design Culture, 14(3), 404-414.

Lee, S. M., \& Kim, C. H.(2007). Research of Baekje culture-products about Chungnam Area National Museum. Journal of the Korea Furniture Society, 18(3), 224-233.

Lee, S. P., \& Kim, S. H.(2007). A study on Hampyeong butterfly festival cultural products design contents using CAD -Focus on Adobe Illustrator CS2. The Research Journal of the Costume Culture, 15(5), 760-769.

Lee, M. K., \& Han, S. H.(2012). Development of textile pattern designs and fashion-cultural products based on Korean traditional rice-cake patterns. Journal of Korean Design Forum, 35, 363-372.

Lee, M. Y.(2005). A study for Seoul-festival generation and systematic support measures. Seoul: Seoul Institute. pp. 162-169.

Ministry of Culture and Tourism(2000). Craft cultural products production and distribution of survey research. Seoul: Author.

Park, M. R., \& Kim, S. Y.(2006). Research on development of tourist souvenirs for Hampyeong Butterfly Festival $=$ Development of natural dyeing pigments and culture goods with useful biological resources. Journal of the Korean Society for Clothing Industry, 8(6), 665-671.

Song, H. R.(2010). A study on fashion design by application of Korean traditional flowered -wall motives - Focused on flower patterns. Journal of The Korean Society of Fashion Design, 10(1), 41-56. 